\title{
Biopsy of Trachea
}

National Cancer Institute

\section{Source}

National Cancer Institute. Biopsy of Trachea. NCI Thesaurus. Code C51631.

Removal of tissue from the trachea for microscopic examination. 